\title{
Purging Exhausted Virus-Specific CD8 T Cell Phenotypes by Somatic Cell Reprogramming
}

\author{
Joshua Chan, ${ }^{1}$ Patrick Y. Kim,2 Emiko Kranz, Yoshiko Nagaoka, YooJin Lee, Jing Wen, Heidi J. Elsaesser, ${ }^{2,3}$ \\ Meng Qin, David G. Brooks, ${ }^{2-4}$ Gene-Errol Ringpis, Irvin S.Y. Chen, ${ }^{1,2}$ and Masakazu Kamata ${ }^{1,5}$
}

\begin{abstract}
Cytotoxic $\mathrm{T}$ cells are critical in controlling virus infections. However, continuous antigen stimulation and negative regulatory factors cause CD8 T cells to enter a dysfunctional state (T cell exhaustion), resulting in viral persistence. We hypothesized that the exhausted $\mathrm{T}$ cell state could be molecularly rejuvenated using a somatic cell reprogramming technology, which is technically able to convert any types of cells to induced pluripotent stem cells (iPSCs), to regenerate functional $\mathrm{T}$ cells capable of purging chronic infection. We generated a new mouse line $\left(\mathrm{B} 6 / 129^{\mathrm{OKSM}}\right)$ in which every somatic cell contains four doxycycline-inducible reprogramming genes (Oct4, Klf4, Sox2, and $c-M y c$ : OKSM), and infected them with lymphocytic choriomeningitis virus (LCMV) clone 13 to establish chronic infection. Exhausted LCMV-specific T cells isolated by flow sorting were successfully reprogrammed ex vivo into iPSCs in the presence of doxycycline. Upon injection into blastocysts and subsequent transfer into foster females, the reprogrammed cells differentiated into functional naive $\mathrm{T}$ cells that maintained their original antigen specificity. These results provide proof of concept that somatic cell reprogramming of exhausted $T$ cells into iPSCs can erase imprints of their previous exhausted state and in turn regenerate functional virus-specific $\mathrm{T}$ cells.
\end{abstract}

Keywords: T cell exhaustion, LCMV, chronic infection, CD8 T cell, iPSC, somatic cell reprogramming

\section{Introduction}

$\mathbf{T}$ CELls, PARTICUlaRly CYTOTOXIC T CELlS (CTLs) serve critical roles in eliminating virus infections. Once naive CTLs, which have not encountered their cognate antigen, are primed by an antigen through $\mathrm{T}$ cell antigen receptor (TCR) expressed on their surface, they undergo dramatic expansion, acquire effector function, and mediate pathogen clearance by killing infected cells. A small population of those cells persist as long-lived memory $\mathrm{T}$ cells at stable levels for many years, providing enhanced protection to the host cell by the rapid recall response following re-exposure to the pathogen. However, in chronic virus infections, continuous antigen stimulation causes the loss of their function ( $\mathrm{T}$ cell exhaustion) characterized by an inability to generate cytotoxic cytokines and factor responses following restimulation, which is a fundamental mechanism facilitating viral persistence.
$\mathrm{T}$ cell exhaustion is a long-term dysfunctional state caused by extensive cellular programming ${ }^{1,2}$ and was originally identified in mice infected with lymphocytic choriomeningitis virus (LCMV). ${ }^{3-5}$ Exhausted T cells have also been observed in response to other virus infections, such as simian immunodeficiency virus (SIV), human immunodeficiency virus (HIV), hepatitis B virus (HBV), and hepatitis C virus (HCV). ${ }^{6-13}$ These cells can be characterized by a significant decrease in cytokine production, such as IL- 2 , IFN- $\gamma$, and TNF- $\alpha$, as well as by cell cycle arrest. ${ }^{14-16}$ Programmed death-1 (PD-1, also known as CD274) was the first proposed exhausted T cell marker. ${ }^{17}$ Rescue of effector functions of exhausted T cells through disruption of PD-1 binding with its ligands (PD-L1 and PD-L2) was demonstrated in various chronically infected animal models, including LCMV-infected mice, ${ }^{17} \mathrm{HIV}$-infected humanized mice, ${ }^{18}$ and SIV-infected nonhuman primates. ${ }^{19,20}$ However, activated $\mathrm{T}$ cells also express PD-1 and remain functional, ${ }^{21}$

\footnotetext{
${ }^{1}$ Division of Hematology and Oncology, ${ }^{2}$ Department of Microbiology, Immunology, and Molecular Genetics, David Geffen School of Medicine at UCLA, Los Angeles, California.

${ }^{3}$ Department of Immunology, University of Toronto, Toronto, Canada.

${ }^{4}$ Princess Margaret Cancer Center, University Health Network, Toronto, Canada.

${ }^{5}$ UCLA AIDS Institute, Los Angeles, California.
} 
indicating that PD-1 is neither a sole marker for exhausted T cells nor an inhibitory surface receptor.

Therapeutic interventions exploiting the PD-1/PD-L1 interaction have been shown to enhance antiviral $T$ cell function and lead to increased control of chronic virus infections in vivo, ${ }^{19,20}$ demonstrating the powerful potential of $\mathrm{T}$ cell immunotherapy. However, since the dysfunctional cellular program remains, once therapeutics are withdrawn, $\mathrm{T}$ cells can again lose antiviral function. ${ }^{22}$ Thus, novel methods to functionally reprogram these exhausted T cells to effectively and durably fight infection are needed to control these infections. Importantly, adoptive transfer of functional memory $\mathrm{T}$ cells effectively eradicates chronic LCMV infection in mice, and HBV and multiple herpes virus infections in humans, ${ }^{23-25}$ suggesting that if exhausted $\mathrm{T}$ cells could effectively be reprogrammed into functional memory $\mathrm{T}$ cells while maintaining their original antigen specificity, it may be feasible to use these cells to control the infection.

Reprogramming of somatic cells into induced pluripotent stem cells (iPSCs) has contributed greatly to our understanding of factors responsible for cell phenotypes and realization of their potential application toward future clinical use. $^{26}$ The exhausted $\mathrm{T}$ cell state is recognized as an alternative, and thus far, irreversible program of T cell differentiation. ${ }^{27}$ Yet, the permanence of the exhausted program and the ability to erase it by de-educating the cells back to a naive state are still unclear. Thus, we hypothesized that molecularly reprogramming exhausted virus-specific T cells into iPSCs and then redifferentiating them into naive $T$ cells could erase their previous dysfunctional imprints while retaining their virus specificity.

Chronic viruses rapidly evolve within an individual. As a result, each individual's antivirus TCR repertoire is person specific. In addition, each individual has a donor-specific human leukocyte antigen (HLA) that limits current attempts to clone and engineer single TCRs ${ }^{28}$ restricted to one HLA haplotype. Thus, a broad and nonspecific approach may not be as effective in engineering immunity to fight chronic virus infections compared with using each individual's own T cells, provided the function of exhausted $\mathrm{T}$ cells can be reprogrammed. Furthermore, the ability to broadly reprogram virus-specific T cells would allow for the breadth of response needed to prevent virus escape from a single reprogrammed epitope or engineered TCR. Although redifferentiated T cells from reprogrammed CTL clones had some ability to kill HIV-infected cells, ${ }^{29}$ the functional status of the cells before reprogramming could not be ascertained in their system used in the report because of the massive ex vivo amplification and TCR stimulation during CTL clone generation. Due to the system being used, it is unclear whether the reprogrammed cells were derived from initially exhausted cells or whether the ex vivo culture restored their function before reprogramming. ${ }^{30}$ Importantly, in those in vitro systems, it is difficult to experimentally measure (1) the extent of molecular and functional restoration compared with parental exhausted $\mathrm{T}$ cells, (2) the identification of functional/transcriptional/ epigenetic imprints retained through reprogramming and how these affect subsequent antiviral function/development, (3) the ability to generate effective immune memory, and ultimately (4) the ability to assess the reprogrammed cells' ability to eliminate the chronic infection from which they were derived. Thus, the efficacy and molecular nature of $\mathrm{T}$ cell reprogramming, whether exhausted $\mathrm{T}$ cells retain specific imprints of their previous differentiation state that then limit antiviral activity, the ability to generate functional $\mathrm{T}$ cells following somatic cell reprogramming, and the utility of using reprogrammed exhausted $\mathrm{T}$ cells to fight chronic virus infection, are critical questions that need to be defined to begin to determine how $\mathrm{T}$ cell reprogramming approaches can be used to treat chronic virus infections.

Our overall goal is to provide proof of concept that exhausted virus-specific $\mathrm{T}$ cells from chronic infection can have their dysfunctional genetic programs erased by a somatic cell reprogramming technology, and that a clean slate for proper and effective antiviral activity as $\mathrm{T}$ cells with their original virus specificity for immunotherapeutic purposes can be instituted. In this study, we used mice infected with LCMV clone 13 (LCMV CL13) to test this hypothesis. This model system has been well recognized as a murine model for establishing chronic viral infection with thorough characterization of $\mathrm{T}$ cell responses that parallel those of HIV, HBV, and HCV infections. ${ }^{12,31,32}$ Thus, our approach for restoring functional antiviral activity from exhausted $\mathrm{T}$ cells could be applicable for other chronic infections.

\section{Materials and Methods}

\section{Cells and reagents}

AinV15 mouse embryonic stem cells (ESCs) were purchased from American Type Culture Collection (ATCC SCRC-1029, Manassas, VA). Mouse ESCs and iPSCs were maintained in ESC medium [15\% FCS (SH30070.03E; GE Healthcare Life Sciences, Marlborough, MA) in Knockout DMEM (10829018; Thermo Fisher Scientific, Canoga Park, CA), with 1\% GlutaMAX (Thermo Fisher Scientific), 1\% MEM nonessential amino acid (Thermo Fisher Scientific), 1,000 U/ml leukemia inhibitory factor (ESG1106; Millipore Sigma, St. Louis, MO), and $0.1 \mathrm{mM}$ 2-mercaptoethanol (EmbryoMax; Millipore Sigma)]. Doxycycline (DOX) was also obtained from Millipore Sigma (D3072). $\gamma$-irradiated mouse embryonic fibroblasts (iMEF) derived from $\mathrm{CF}-1$ mouse line were purchased from MTI-GlobalStem (GSC6301G, Gaithersburg, MD). Embryoid bodies were generated as reported. ${ }^{33}$ Antibodies were purchased from the following sources: SSEA-1 (MC-480; BioLegend, San Diego, CA), Nanog (M55-312; BD Biosciences, San Jose, CA), Fibroblast marker (ER-TR7; Santa Cruz Biotechnology, Dallas, TX), mouse CD19 (1D3; Thermo Fisher), mouse/human B220 (RA3-6B2, BioLegend), mouse CD3 (17A2; BioLegend), mouse CD4 (RM4-5; BioLegend), mouse CD8 (53-6.7; BioLegend), mouse CD62 L (MEL-14; BioLegend), mouse CD25 (PC61; BioLegend), mouse PD-1 (29F.1A12; BioLegend), and CD44 (IM7; BioLegend). Matrigel qualified for human ESC culture was purchased from BD Biosciences. Magnetic beads coated with anti-CD3 and anti-CD28 antibodies were purchased from Thermo Fisher (Dynabeads mouse T-activator CD3/CD28, Thermo Fisher Scientific). LCMV gp33-41 (KAVYNFATM) tetramer and LCMV gp276-286 (SYVENPGGYCL) tetramer, both of which are mouse $\mathrm{H}-2 \mathrm{D}^{\mathrm{b}}$ restricted, were generated by the NIH Tetramer Core Facility at Emory University. The latter was used as a negative control.

The primers were purchased from IDT (Coralville, IA; Table 1). 
Table 1. Primer Sequences Used in PCR Analysis

\begin{tabular}{|c|c|}
\hline \multicolumn{2}{|c|}{ Target: mouse TCR- $\beta$ chain } \\
\hline$T C R \beta-\mathrm{D} 1 \mathrm{U}-\mathrm{S}$ & GAGGAGCAGCTTATCTGGTGGTTT \\
\hline$T C R \beta-\mathrm{J} 1 \mathrm{D}-\mathrm{A}$ & САСАAССССТССАGTCAGAAATG \\
\hline$T C R \beta-\mathrm{J} 2 \mathrm{D}-\mathrm{A}$ & TGAGAGCTGTCTCCTACTATCGATT \\
\hline $\mathrm{D} \beta 2(\mathrm{E})$ & CAGTCAGACAAACCTCTCTGCCAC \\
\hline $\mathrm{D} \beta$ sense & GCTTATCTGGTGGTTTCTTCCAGC \\
\hline $\mathrm{J} \beta$ reverse & GCAGAGTTCCATTTCAGAACCTAGC \\
\hline \multicolumn{2}{|c|}{ Target: mouse immunoglobulin } \\
\hline $\mathrm{VH}$ & $\begin{array}{l}\text { CGAGCTCTCCARCACAGCCTWC } \\
\text { ATGCARCTCARC }\end{array}$ \\
\hline $\mathrm{J} 3$ & $\begin{array}{l}\text { GTCTAGATTCTCACAAGAGTCCG } \\
\text { ATAGACCCTGG }\end{array}$ \\
\hline \multicolumn{2}{|l|}{ Target: ROSA26 } \\
\hline & GCG AAG AGT TTG TCC TCA ACC \\
\hline oIM & AAA GTC GCT CTG AGT TGT TAT \\
\hline oIMR8546 & GGA GCG GGA GAA ATG GAT ATG \\
\hline
\end{tabular}

\section{Animals}

Animal research described in the study was conducted under UCLA's Chancellor's Animal Research Committee (Institutional Animal Care and Use Committee [IACUC]) in accordance with guidelines for housing and care of laboratory animals of the National Institutes of Health (NIH) and the Association for the Assessment and Accreditation of Laboratory Animal Care (AALAC) International. Chimeric mice from iPSCs were generated at the UCLA Transgenic Mouse Core and CSMC Mouse Genetics Core. JAX011011 established by Dr. Jaenisch, ${ }^{34}$ containing four DOX-inducible mouse reprogramming genes (Oct4, Sox2, Klf4, and $c-M y c$ : OSKM) from Collal locus was purchased from the Jackson Laboratory (Bar Harbor, ME). Transgenic mouse carrying LCMV gp33-specific TCR (P14) was purchased from UCLA DLAM breeding colony service.

\section{Generation of a mouse strain containing four DOX-inducible reprogramming genes}

A novel mouse line [B6129P2/OlaHsd-Gt(ROSA) $26^{\text {rtTA/Oct4-Klf4-Sox2-cMyc] }}$ abbreviated as B6/129 ${ }^{\mathrm{OKSM}}$ ] in which every somatic cell contains four DOX-inducible reprogramming genes was established as follows. AinV15 cells were differentiated into fibroblast-like cells by culturing in 10\% FCS/DMEM for 2 weeks. Differentiation status was confirmed by fibroblast-like morphology and expression of fibroblast marker, ER-TR7. Cells were transduced with a polycystronic lentiviral vector encoding reprogramming genes (STEM-CCA vector obtained from Dr. Mostoslavsky ${ }^{35}$ ) and replated on iMEF-feeder cells at day 7 after vector transduction. Reprogramming into iPSCs was induced by culturing those cells for 2 weeks in ESC medium under the presence of $1 \mu \mathrm{g} / \mathrm{ml} \mathrm{DOX}$. ESC-like colonies were selected and monitored for the expression of pluripotent stem cell markers (SSEA1 and Nanog) by standard fluorescence microscopy as well as flow cytometry. After 10 passages, three independent clones positive for those markers were selected and used for generation of chimeric mice to validate pluripotency. Resulting chimeric mice were then crossbred with B6 mice, and F1 hybrids with an agouti coat derived from the 129P2/OlaHsd strain were crossbred for $>10$ generations to establish an inbred mouse line carrying a single copy of the STEM-CCA insert in the same allele (i.e., homozygote) and enabling induction of ESC-like colony formation from peripheral blood cells with high efficiency in the presence of DOX. Integrated vector copy number was assessed as reported previously. ${ }^{36}$ Insertional mutation of reverse tetracyclinecontrolled transactivator in ROSA26 loci was monitored by genotyping using oIMR8052, oIMR8545, and oIMR8546 primers as recommended by the Jackson Laboratory.

\section{Somatic cell reprogramming of exhausted LCMV-specific CD8 T cells}

Isolation of LCMV-specific CD8 T cells was performed as follows. Briefly, five B6/129 ${ }^{\mathrm{OKSM}}$ mice were infected with LCMV CL13 to induce chronic infection. As a positive control, four additional B6/129 ${ }^{\mathrm{OKSM}}$ mice were infected with LCMV Armstrong (ARM). ${ }^{37}$ Splenocytes were isolated from the infected mice at days 45 or 22 after infection of LCMV CL13 or LCMV ARM, respectively. Triple-positive cells for antimouse CD3 and CD8 antibodies as well as LCMV gp33 tetramer, were flow sorted for reprogramming. The status of $\mathrm{T}$ cell exhaustion was confirmed by high levels of PD-1 expression and poor responsiveness to LCMV gp33-41 peptide pulsing (data not shown). Reprogramming of LCMV gp33specific CD8 T cells was mediated by culturing cells on iMEFfeeder cells or Matrigel under the presence of $1 \mu \mathrm{g} / \mathrm{ml}$ DOX. To isolate homogeneous reprogrammed cell lines, single colonies with ESC-like morphologies, characterized by round colonies with a clear and bright border, ${ }^{38}$ were passed onto six-well cell culture plates preplated with iMEF-feeder cells with no DOX. The single colonies were passaged every 2-4 days for $>10$ times until each clone had uniform ESC-like morphologies.

\section{PCR analyses for immunoglobulin and TCR D $\beta$ gene rearrangements}

Gene rearrangements in immunoglobulin for B cells and TCR- $\beta$ chain loci for T cells were analyzed by PCR using genomic DNA isolated from clones and a pair of specific primers. Genomic DNA was extracted with the DNeasy Kit (69504; QIAGEN, Hilden, Germany). One primer set for B cells (VHJ558 and J3) and three primer sets for T cells [TCR $\beta$-D1 U$\mathrm{S} \& T C R \beta-\mathrm{D} 1 \mathrm{U}-\mathrm{A}, \mathrm{D} \beta 2(\mathrm{E}) \& T C R \beta-\mathrm{J} 2 \mathrm{D}-\mathrm{A}, T C R \beta-\mathrm{D} 1 \mathrm{U}-\mathrm{S} \&$ $T C R \beta-\mathrm{J} 2 \mathrm{D}-\mathrm{A}]$ were used to identify gene rearrangements of immunoglobulin and TCR $\beta$ chain, respectively. The PCR products were separated by gel electrophoresis.

\section{Flow cytometry}

Immunostained cells were acquired on LSRFortessa Flow Cytometer using FACSDiva software (BD Biosciences). Data were analyzed using FlowJo software (FlowJo, LLC, Ashland, OR). Cell sorting was performed by the CFAR Flow Cytometry Core Facility at UCLA using BD Aria III.

\section{Results}

Establishing B6/129 ${ }^{\text {KSM }}$ mouse strain that exhibits high levels of reprogrammed colony formation from peripheral $B$ and $T$ cells

After the discovery of a somatic cell reprogramming technology by the transduction of four genes (Oct4, Klf4, Sox 2 , and $c-M y c)$, various additional factors as well as induction methods 
have been developed and optimized. ${ }^{39-42,43}$ However, the generation of iPSCs is still inefficient, with just $1 \%$ of the original cell population forming iPSCs on average, and an even lower percentage forming T cells. ${ }^{39,44,45}$

$\mathrm{T}$ cell exhaustion is a dysfunctional state of unresponsiveness to antigen stimulation, thus, reprogramming of exhausted $\mathrm{T}$ cells is anticipated to be challenging. Transgenic mouse strains with the four genes mentioned above have been developed and have shown successful reprogramming from rare blood cell populations. ${ }^{34,45}$ One of the mouse lines, JAX011011, was tested for reprogramming of peripheral $\mathrm{T}$ cells, but the approach was unsuccessful. We attempted to establish a new mouse line that allowed highly efficient reprogramming of $\mathrm{T}$ cells isolated from peripheral blood (Fig. 1A). Briefly, fibroblast-like cells were generated by differentiating a mouse ESC line, AinV15 (ATCC:SCRC1029) derived from 129P2/OlaHsd ${ }^{\mathrm{Gt}(\mathrm{ROSA}) 26 \mathrm{Sor} r t \mathrm{TA}}$ mouse, then stably expressing reverse tetracycline transactivator (rtTA), and transducing it with a polycistronic lentiviral vector encoding the above four reprogramming genes with an order of Oct4, Klf4, Sox2, and $c-M y c$ (OKSM) under the DOX-inducible promoter (STEM-CCA ${ }^{35}$ ). Those cells were then plated on iMEFs and cultured for 2 weeks in ESC medium supplemented with $1 \mu \mathrm{g} / \mathrm{ml}$ DOX for induction of reprogramming gene expression. Three independent colonies exhibiting typical mouse ESC-like morphology were replated on iMEFs and selected based on stable expression of plu- ripotent stem cell markers (SSEA1, SSEA3, SSEA4, and Nanog) (data not shown) for chimeric mouse generation. A total of 23 chimera mice out of 28 live births were derived. The chimeric offspring manifested the distinctive mixed coat colors of the donor blastocysts (B6: black) and host genotypes (129P2/OlaHsd: mosaic coat colors of agouti, white, chinchilla, and black) (Fig. 1B). Generation of secondary iPSCs $\left(2^{\circ} \text { iPSCs }\right)^{45,46}$ obtained by culturing cells originated from STEM-CCA vector-transduced AinV15 cells in the presence of DOX, was confirmed using tail-tip fibroblasts. ESC-like phenotypes of those $2^{\circ}$ iPSCs were verified by the expression of SSEA1 and Nanog, and by differentiation in embryoid bodies (Fig. 1C, D). Three chimeric mice with high levels of coat color chimerism $(>90 \%)$ were selected and bred with B6 mice for generation of F1 hybrids. F1 hybrids with an agouti coat were then crossbred for $>10$ generations to establish a stable mouse line carrying a single copy of the OKSM cassette, which was derived from STEM-CCA lentiviral vector, in the same locus homozygously, as well as inducing high levels of ESC-like colony formation from peripheral blood cells. This novel mouse strain was named as B6129P2/OlaHsd-Gt(ROSA)26rtTA/Oct4-Klf4-Sox2-cMyc (abbreviated as $\mathrm{B} 6 / 129^{\mathrm{OKSM}}$ ) following the rules for strain nomenclature of genetically engineered animals. ${ }^{47}$

We first compared reprogramming efficiencies of TTFs and peripheral blood cells obtained from our mice (B6/ $129^{\mathrm{OKSM}}$ ) versus JAX011011 (Fig. 2). Reprogramming of
A

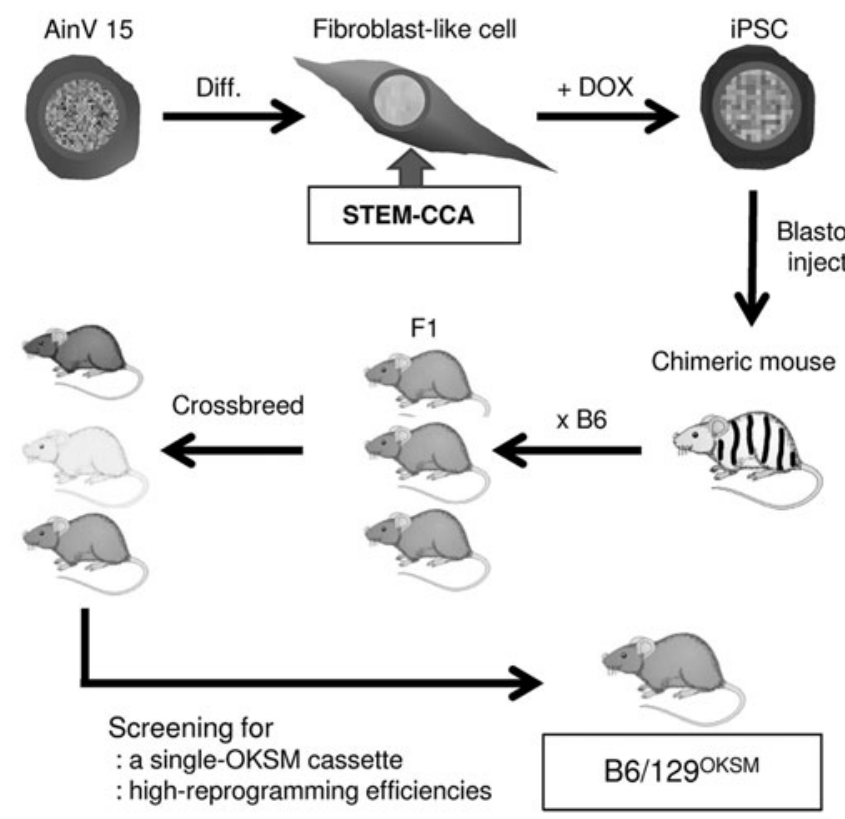

B
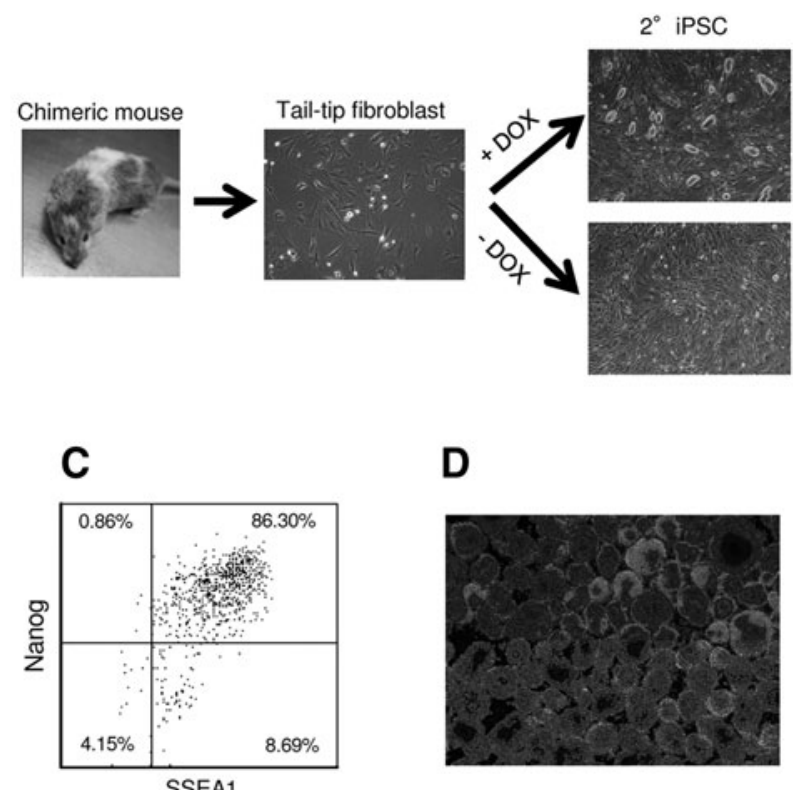

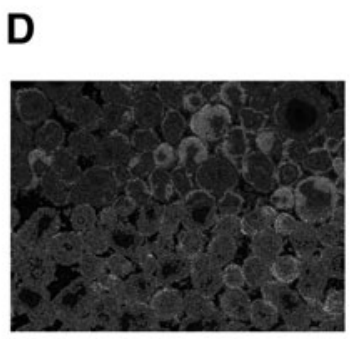

FIG. 1. Establishment of B6/129 ${ }^{\mathrm{OKSM}}$ mouse line. (A) Schematic illustration of B6/129 ${ }^{\mathrm{OKSM}}$ mouse generation. We first established a DOX-reprogrammable fibroblast-like cell line originated from AinV15 mouse ESCs by transduction of STEMCCA lentiviral vector encoding four DOX-inducible mouse reprogramming genes (Oct4, Klf4, Sox2, and $c$-Myc). Chimeric mice were generated by the injection of 8-12 established iPSCs into a B6 mouse blastocyst. The mice were bred with B6 mice to obtain F1 hybrids derived from 129P2/OlaHsd strain (agouti coat). F1 hybrids were then crossbred for $>10$ generations until we established a stable mouse line carrying a single copy of a reprogramming gene cassette introduced by STEM-CCA lentiviral vector homozygously and enabling induction of ESC-like colony formation from peripheral blood cells with high efficiency in the presence of DOX. DOX: doxycycline. Diff.: differentiation. (B) Fibroblasts were isolated from tail-tip biopsies of chimeric mice and exposed to $1 \mu \mathrm{g} / \mathrm{ml}$ of DOX for $2^{\circ}$ iPSC induction. No $2^{\circ}$ iPSC formation was seen with no DOX addition. (C) Expression of two pluripotent stem cell markers (Nanog and SSEA1) in $2^{\circ}$ iPSCs. (D) Embryoid bodies generated from $2^{\circ}$ iPSCs. iPSC, induced pluripotent stem cell. 
A

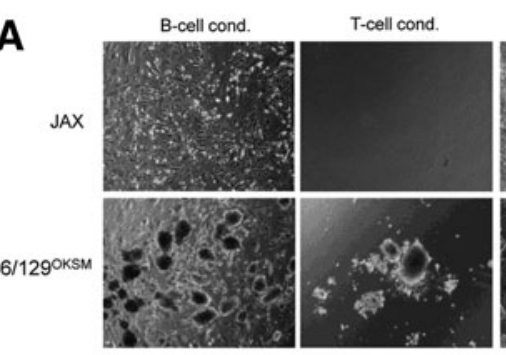

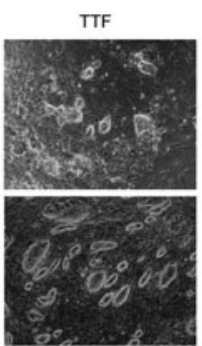

B

\begin{tabular}{|c|c|}
\hline Mouse \# & Efficiency (TTF) \\
\hline JAX\#1 & $0.003 \%$ \\
\hline JAX \#2 & $0.033 \%$ \\
\hline JAX \#3 & $0.000 \%$ \\
\hline B6/129OKSM \#1 & $0.363 \%$ \\
\hline B6/129OKSM \#2 & $0.413 \%$ \\
\hline
\end{tabular}

C

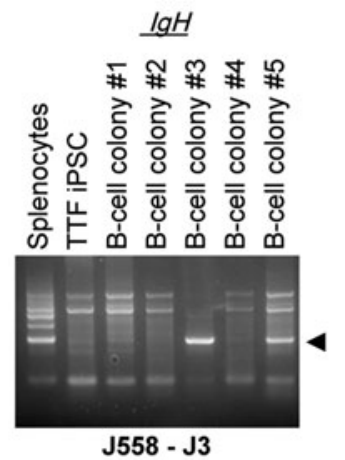

$\underline{T C R \beta}$

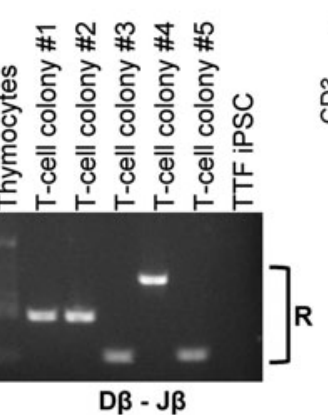

D

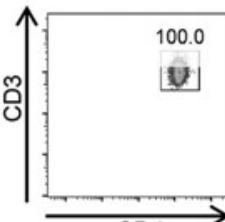

CD4

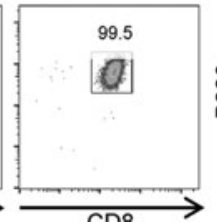

CD8

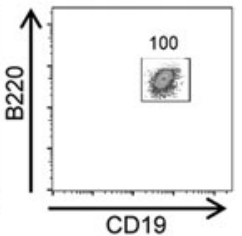

$R$

$\mathbf{E}$

\begin{tabular}{|c|c|c|c|}
\hline Mouse \# & CD19+/B220+ B cell & CD4+T cell & CD8+ T cell \\
\hline JAX\#1 & $\mathrm{NC}$ & $\mathrm{NC}$ & $\mathrm{NC}$ \\
\hline JAX\#2 & $\mathrm{NC}$ & $\mathrm{NC}$ & $\mathrm{NC}$ \\
\hline JAX\#3 & $\mathrm{NC}$ & $\mathrm{NC}$ & $\mathrm{NC}$ \\
\hline B6/1290KSM \#1 & $0.6 \%$ & $0.9 \%$ & $1.4 \%$ \\
\hline B6/1290KSM \#2 & $0.2 \%$ & $0.3 \%$ & $0.9 \%$ \\
\hline
\end{tabular}

FIG. 2. Highly efficient induction of $2^{\circ} \mathrm{iPSC}$ from peripheral blood cells of $\mathrm{B} 6 / 129^{\mathrm{OKSM}}$ mice. (A) TTFs or peripheral blood cells were obtained from B6/129 $9^{\mathrm{OKSM}}$ mice described in Figure 1 or JAX011011 (JAX), and cultured in the presence of DOX. For efficient B cell and T cell expansion ex vivo, anti-CD40 antibody, IL-4, IL-7, and BAFF (B cell expansion condition: B cell cond.), or anti-CD3/CD28 antibody and IL-2 (T cell expansion condition: T cell cond.) were added together with DOX during reprogramming, respectively. Reprogramming of cells in the $\mathrm{T}$ cell expansion condition was performed on Matrigel-coated plates. TTFs or cells in the B cell expansion condition were reprogrammed on iMEF-coated plates. Round ESC-like colonies were visible after 2 weeks. (B) Reprogramming efficiency of TTFs was determined by the total number of round ESC-like colonies divided by the total number of TTFs plated for reprogramming (30,000 cells) at week 3 postinduction. (C) Gene rearrangements of immunoglobulins ( $\mathrm{J} 558-\mathrm{J} 3)$ or $T C R-\beta$ chain genes $(\mathrm{D} \beta-\mathrm{J} \beta)$ in reprogrammed cells obtained from $\mathrm{B}$ cell or $\mathrm{T}$ cell expansion conditions, respectively, were analyzed by PCR. Splenocytes and thymocytes obtained from B6/129 $9^{\mathrm{OKSM}}$ mice were used as positive controls, respectively. iPSCs derived from TTF were used as a negative control. Arrowhead: bands from rearranged immunoglobulin gene. R: bands from rearranged $T C R-\beta$ chain. (D) $\mathrm{CD}^{+} / \mathrm{CD}^{+} \mathrm{T}$ cells, $\mathrm{CD}^{+} / \mathrm{CD}^{+} \mathrm{T}$ cells, and $\mathrm{CD} 19^{+} / \mathrm{B} 220^{+} \mathrm{B}$ cells were isolated from splenocytes of B6/129 ${ }^{\mathrm{OKSM}}$ mice with magnetic beads. Each purity was determined by flow cytometry. (E) Purified $\mathrm{CD} 19^{+} / \mathrm{B} 220^{+} \mathrm{B}$ cells, $\mathrm{CD} 4^{+} \mathrm{T}$ cells, and $\mathrm{CD} 8^{+} \mathrm{T}$ cells $(30,000$ cells) were reprogrammed for 3 weeks in the conditions described in Figure 2A. Plates were fixed, and reprogramming efficiency was calculated as described in Figure 2B. NC, no colony; TTF, tail-tip fibroblast.

TTFs and blood cells in the B cell expansion condition was successfully performed on iMEFs as reported previously. ${ }^{38}$ This approach was unsuccessful for blood cells in the T cell expansion condition due to potent cytotoxic effects against iMEFs; most of the iMEFs were killed off within a week to 10 days and detached from the culture plate together with partially reprogrammed cells (data not shown). We, therefore, used plates coated with Matrigel for reprogramming of cells in the T cell expansion condition.

Successful ESC-like colony formation with TTFs was achieved with both mouse strains (Fig. 2A), but the reprogramming efficiencies of our new mouse strain was 10- to 100fold higher compared with those of JAX011011 (Fig. 2B). Similarly, a great number of ESC-like colonies were confirmed with blood cells from our mice, but no colonies were seen with blood cells from JAX011011, in both culture conditions. We also tested the reprogramming efficiency in iMEF-conditioned medium, which would support efficient growth of reprogrammed cells, but there was no improvement (data not shown). To confirm whether blood cell-derived colonies originated from B or T cells, the rearrangement status of immunoglobulin heavy $(I g H)$ locus and T cell receptor $\beta(T C R-\beta)$ locus was assessed by PCR with genomic DNA using specific primer sets for each locus, respectively (Fig. 2C). Two out of five colonies in the B cell expansion condition contained rearranged $\mathrm{IgH}$ genes, whereas all five colonies in the T cell expansion condition contained rearranged TCR- $\beta$ genes. Although we analyzed an additional 29 colonies in the B cell expansion condition, only $40 \%$ of total colonies (12 out of 29) contained rearranged $\mathrm{IgH}$ genes, indicating that other types of blood cells can be more efficiently reprogrammed compared to B cells in the B cell expansion condition. A strict 
comparison of reprogramming efficiencies of peripheral B and $\mathrm{T}$ cells was performed with magnetic bead-purified populations. The purity of each population was $>99.5 \%$ (Fig. 2D). High levels of B and T cell reprogramming were seen with our mice, but no colony formation was observed with JAX011011. As expected, slightly higher levels of reprogramming were confirmed in the $\mathrm{T}$ cell population, especially with CD8 $\mathrm{T}$ cells, compared to the $\mathrm{B}$ cell population (Fig. 2E, CD4:CD8 $=0.9 \%: 1.4 \%$ or $0.3 \%: 0.9 \%$ ).

\section{Exhausted LCMV gp33-specific T cells successfully reprogram into iPSCs and redifferentiate into functional $T$ cells maintaining original antigen specificity}

The B6/129 ${ }^{\text {OKSM }}$ mouse strain described above allowed highly efficient reprogramming of blood cells, especially $\mathrm{T}$ cells, by simply culturing them in the presence of DOX. Using this mouse, we next determined whether exhausted $\mathrm{T}$ cells can reprogram into iPSCs while maintaining their original antigen specificity. B6/129 ${ }^{\mathrm{OKSM}}$ mice were infected with either LCMV CL13, which induces chronic infection, or LCMV ARM, which causes acute infection ${ }^{48}$ as a positive control. LCMV gp33-specific CD8 T cells were FACS sorted on day 22 for LCMV ARM and day 45 for LCMV CL13 after infection (Fig. 3A). Postsort analysis indicated that the sorting efficiencies were $>99.0 \%$ in both cases. $\mathrm{T}$ cell exhaustion of the cells obtained from LCMV CL13-infected mice was verified by high levels of PD-1 expression and poor responsiveness to LCMV gp33-41 peptide pulsing (data not shown). Those cells were then reprogrammed on iMEF-coated and Matrigel-coated plates in the culture conditions described above.

ESC-like colonies appeared after around 3 weeks in both iMEF- and Matrigel-coated plates (Fig. 3B), but fewer colonies were seen in the latter (data not shown). Colonies double positive for SSEA1 and Nanog were selected and tested for their differentiation ability in embryoid bodies (Fig. 3C). Genomic DNA from each colony was extracted and processed for PCR-based TCR- $\beta$ locus analysis (Fig. 4A, B). We successfully established 57 clones from $T$ cells of LCMV ARM-infected mice and 33 clones from T cells of LCMV CL13-infected mice. Reprogramming efficiencies were much lower than those of pan CD8 T cells shown in Figure 2E; at $0.048 \%$ for LCMV ARM and $0.022 \%$ for LCMV CL13, respectively.

Three clones (Fig. 4B, Clone\#1-3), derived from LCMV CL13-infected mice with different rearranged TCR- $\beta$ patterns, were tested for their ability to differentiate into functional $\mathrm{T}$ cells while maintaining their original antigen specificity through chimeric mouse generation. To monitor progeny cells derived from the original cells used for injection into blastocysts, the clones were genetically labeled by an FG12 lentiviral vector encoding EGFP. ${ }^{49}$ A total of 9 chimeric mice out of 54 live births were derived from those clones $(2,5$, and 2 mice from clones \#1, 2, and 3, respectively), indicating that they were derived from pluripotent precursors, that is, iPSCs. Overall, chimerisms, evaluated by visual assessment of coat color, were quite low compared with those from iPSCs originated from fibroblast-like cells transduced with STEM-CCA lentiviral vector (compare
A

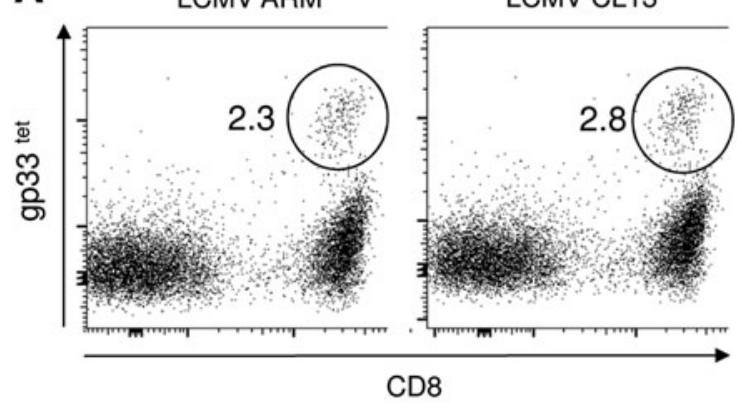

B

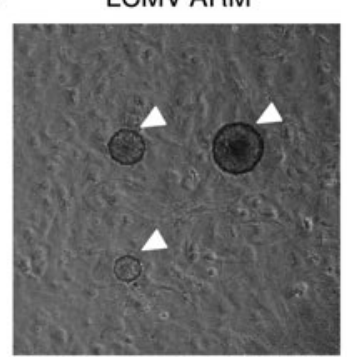

LCMV CL13

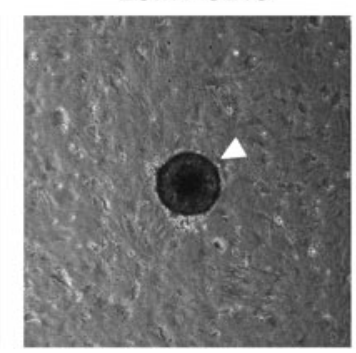

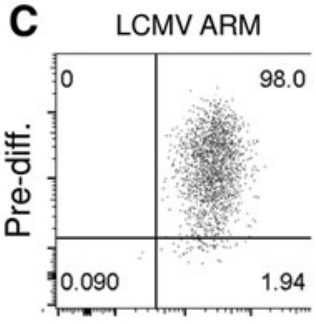
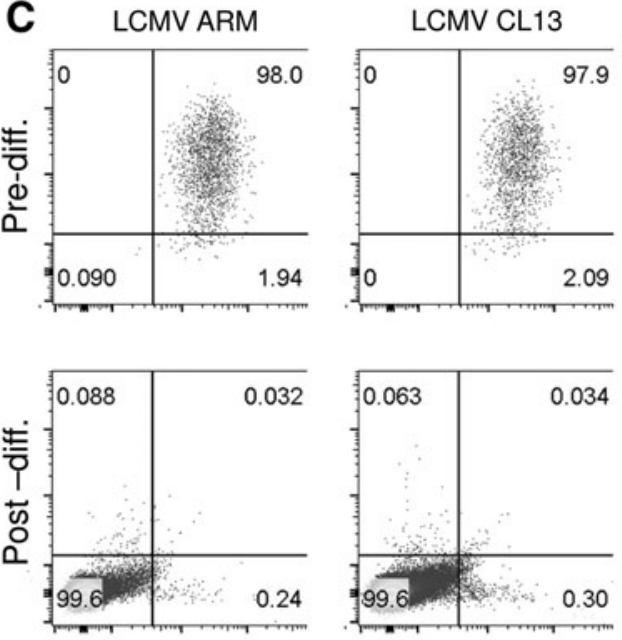

$\infty$
W
$\mathbb{1}$

Nanog

FIG. 3. Reprogramming of exhausted LCMV-specific CD8 T cells. (A) B6/129 ${ }^{\text {OKSM }}$ mice were infected with either LCMV ARM (inducing acute infection) or LCMV CL13 (inducing chronic infection). Splenocytes were isolated on day 22 or 45 following infection of LCMV ARM or LCMV CL13, respectively, and stained with mouse CD3 and mouse CD8 antibodies together with LCMV gp33-specific tetramer (gp33 tet) for flow sorting. Of these, 30,000 sorted cells (>99.0\% purity) were reprogrammed in the presence of $1 \mu \mathrm{g} / \mathrm{ml}$ of DOX. The number indicates $\%$ gp33 tetramer+ cells in total splenic CD8 T cells. (B) Morphologies of reprogrammed ESC-like colonies (arrowheads) 3 weeks after induction of reprogramming. Magnification: $50 \times$. (C) Expression of pluripotent stem cell markers, SSEA1 and Nanog, in reprogrammed cells pre- and postdifferentiation in embryoid bodies for 14 days. LCMV, lymphocytic choriomeningitis virus. 


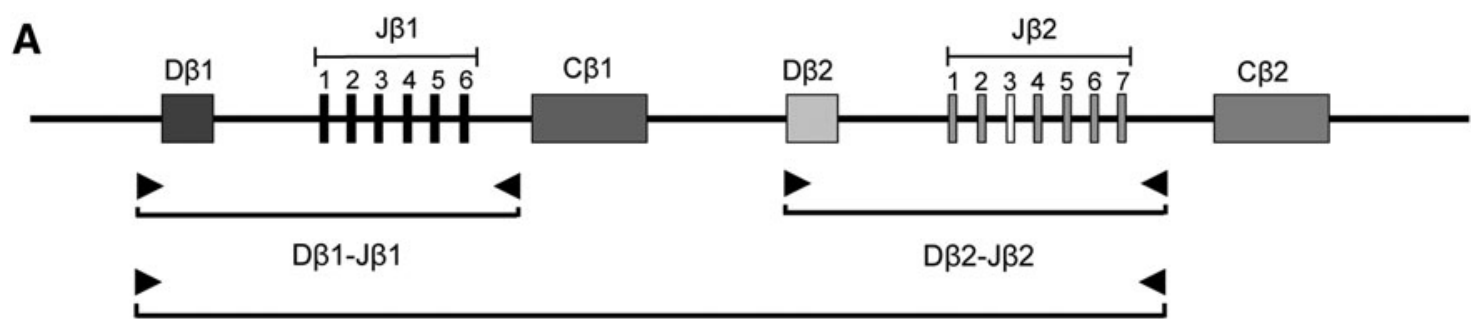

$D \beta 1-J \beta 2$
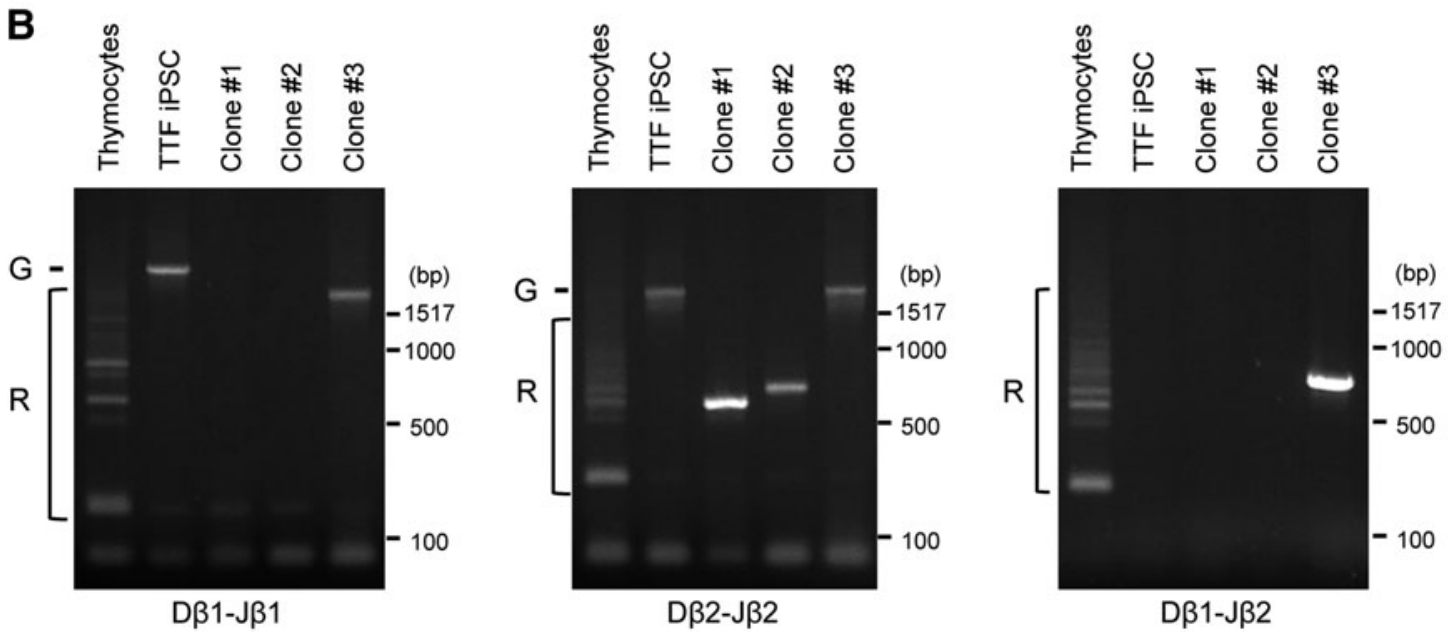

FIG. 4. PCR-based analysis of TCR- $\beta$ chain rearrangement in ESC-like clones. Total genomic DNAs were extracted from reprogrammed ESC-like clones established from exhausted LCMV gp33-specific T cells isolated from LCMV CL13infected B6/129 $9^{\mathrm{OKSM}}$ mice. (A) Schematic presentation of PCR-based TCR- $\beta$ locus rearrangement assay. "D" and "J": diversity and joining gene segments, respectively. Primer combinations: TCR $\beta$-D1 U-S \& TCR $\beta-\mathrm{J} 1 \mathrm{D}-\mathrm{A}$ for $\mathrm{D} \beta 1-\mathrm{J} \beta 1$, $\mathrm{D} \beta 2(\mathrm{E}) \& T C R \beta-\mathrm{J} 2 \mathrm{D}-\mathrm{A}$ for $\mathrm{D} \beta 2-\mathrm{J} \beta 2$, and $T C R \beta-\mathrm{D} 1 \mathrm{U}-\mathrm{S} \& T C R \beta-\mathrm{J} 2 \mathrm{D}-\mathrm{A}$ for $\mathrm{D} \beta 1-\mathrm{J} \beta 2$. Target regions of each primer are indicated by arrowheads. (B) Representative gel pictures of amplification products from three clones obtained from reprogrammed LCMV gp33-specific exhausted T cells. "G" and " $R$ " show sizes of $T C R$ - $\beta$ chain from germline (i.e., TTF) or T cells, respectively. Thymocytes from naive $\mathrm{B} 6 / 129^{\mathrm{OKSM}}$ mice were used as a positive control for rearranged TCR- $\beta$ chain. iPSCs derived from TTF were used as a negative control.

mouse pictures from Figs. 1B and 5A). Of those clones, peripheral CD8 T cells derived from clone \#3 contained LCMV gp33-specific CD8 T cells [Fig. 5B, $3.0 \%$ in total $\mathrm{CD}^{+} / \mathrm{CD}^{+}$ T cell population (red box)]. As expected, $\mathrm{EGFP}^{+}$cells in the $\mathrm{CD}^{+} / \mathrm{CD}^{+}$population were also positive for LCMV gp33 tetramer (Fig. 5B), indicating that iPSCs derived from exhausted LCMV gp33-specific T cells were successfully redifferentiated into CD8 $\mathrm{T}$ cells that maintained their original antigen specificity. Importantly, those CD8 T cells positive for EGFP and LCMV gp33 tetramer expressed cell surface markers for naive $\mathrm{T}$ cells $\left[\mathrm{CD} 62 \mathrm{~L}^{+} / \mathrm{CD} 44^{\mathrm{lo}} / \mathrm{CD} 25^{-}\right.$, and $\mathrm{CD} 127^{+}$(data not shown)] and no PD-1, which is one of the T cell exhaustion markers, similar to those in the EGFP population (Fig. 5C). These results indicate that exhausted LCMV gp33-specific CD8 $\mathrm{T}$ cells can reprogram into iPSCs and restore a naive $T$ cell surface phenotype while maintaining their original antigen specificity. We could not confirm EGFP $^{+} \mathrm{T}$ cells in chimeric mice originated from clones \#1 and \#2, possibly due to low levels of chimerism from those clones $\left(<0.1 \% \mathrm{EGFP}^{+}\right.$cells in peripheral blood).

Antigen-specific T cell responses of those LCMV gp33specific CD8 T cells were assessed by LCMV gp33-41 peptide pulsing in the presence of anti-mouse CD28 antibody,
IL-7, and IL-15 (Fig. 6). Expansion of LCMV gp33-specific CD8 T cells was verified upon peptide pulsing [Fig. 6A, gp33 tetramer-positive cells in $10^{6} \mathrm{CD} 3 \mathrm{~T}$ cells: 8,700 cells (prepulsing) vs. 110,000 cells (postpulsing)]. A majority of the LCMV gp33-specific CD8 T cells exhibited a surface phenotype of activated effector T cells (Fig. 6B, 40\% PD- $1^{+} /$ $\mathrm{CD} 25^{+}$). A similar observation was made in CD8 T cells from $\mathrm{P} 14^{+} \mathrm{B} 6 / 129^{\mathrm{OKSM}}$, which was generated by crossbreeding B6/129 ${ }^{\mathrm{OKSM}}$ mice with transgenic mice carrying an LCMV gp33-specific TCR (P14) gene. ${ }^{50}$ No or minimal levels of LCMV gp33-specific CD8 T cell response was detected from CD8 T cell populations that were negative for LCMV gp33 tetramer in the chimera or naive $\mathrm{B} 6 / 129^{\mathrm{OKSM}}$ mice. In conclusion, these results indicate that exhausted LCMV gp33-specific CD8 T cells can reprogram into iPSCs and redifferentiate into functional naive $\mathrm{T}$ cells with their original antigen specificity.

\section{Discussion}

We assessed the feasibility of restoring functional effector $\mathrm{T}$ cell activity to exhausted antigen-specific CD8 T cells while maintaining their original antigen specificity, by a 
A

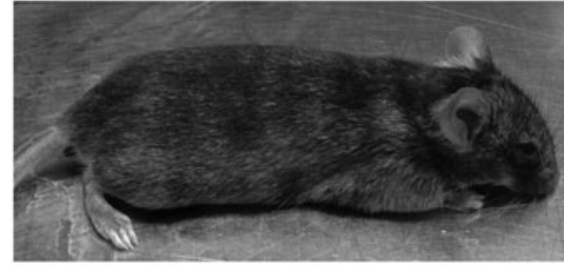

Clone\#3

Chimera

B

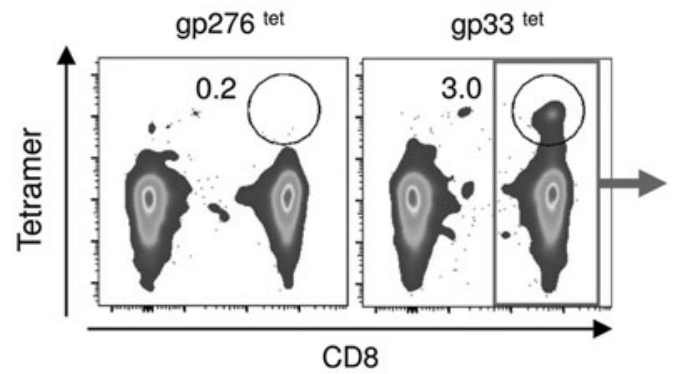

C

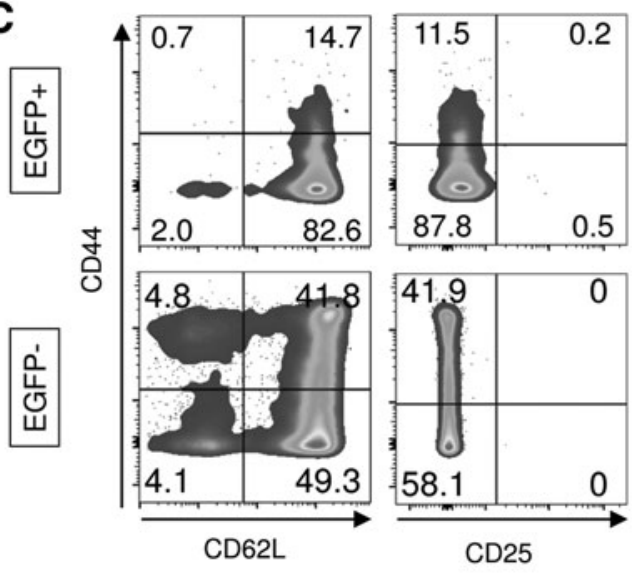

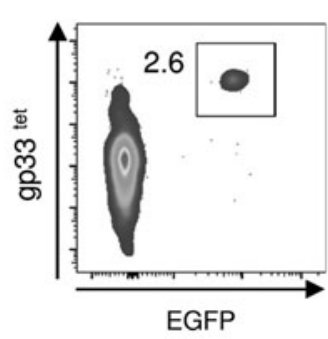

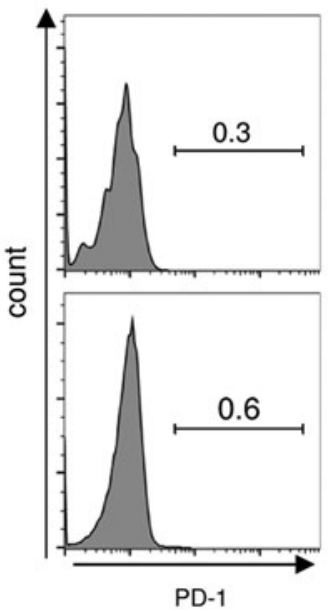

FIG. 5. Redifferentiation of iPSCs derived from exhausted LCMV-specific T cells into $\mathrm{T}$ cells with a naive phenotype in vivo. (A) iPSCs (clone \#3) originated from exhausted LCMV gp33-specific T cells were injected into B6 blastocysts to generate chimeric mice after being genetically labeled with EGFP by an FG12 lentiviral vector. Agouti color indicates the percentage of iPSC contribution to the animal. (B) LCMV gp33specific CD8 $\mathrm{T}$ cells in peripheral blood obtained from the chimeric mouse shown in Figure 5A were analyzed by flow cytometry following staining with mouse CD3 and CD8 antibodies together with LCMVspecific gp33 tetramer (gp33 $\left.{ }^{\text {tet }}\right)$. Numbers in flow panels indicate\% of tetramer+ CD8 T cells in total CD8 T cell population. LCMV gp276-specific tetramer (gp276 ${ }^{\text {tet }}$ ) was used as a negative control. (C) EGFP $^{+}$(iPSC derived) or $\mathrm{EGFP}^{-}$(donor derived) population shown in Figure 5B was further analyzed for $\mathrm{T}$ cell surface phenotypes using antibodies against CD44, CD62L, CD25, PD-1, and CD127 (data not shown). CD62L+CD44 ${ }^{10}$ : naive $\mathrm{T}$ cell, $\mathrm{CD} 62 \mathrm{~L}+\mathrm{CD} 44^{\text {int-hii: }}$ activated or central memory, CD62 L-CD44hi: effector memory. Numbers indicate the percentage of the parent gate. somatic cell reprogramming technology. Using a murine chronic infection model, our results indicate that (1) exhausted antigen-specific CD8 T cells can be reprogrammed into iPSCs, (2) those iPSCs can redifferentiate into CD8 T cells with a naive cell surface phenotype and parental antigen specificity, and (3) those T cells can functionally respond to antigen-specific stimulation. These results provide proof of concept for reversal of the exhausted $\mathrm{T}$ cell program by cleaning their previous dysfunctional state through a somatic cell reprogramming technology.

The mouse strain, B6/129 ${ }^{\text {KKSM }}$, used in this research showed superior reprogramming efficiencies from peripheral B and T cells compared with JAX011011, which was developed by Dr. Rudolf Jaenisch with a similar concept. ${ }^{34}$ Both strains contain single copies of four DOX-inducible mouse reprogramming genes, but the order of those genes is different. For our B6/129 ${ }^{\text {OKSM }}$ mouse strain, we used a STEM-CCA lentiviral vector to transduce a cassette encoding four reprogramming genes with an order of Oct4, Klf4, Sox2, and $c-M y c$ (OKSM), whereas JAX011011 contains a different cassette with an order of Oct4, Sox2, Klf4, and $c$-Myc (OSKM). Comparative analysis of the JAX011011 strain $^{34}$ and another mouse strain carrying a single copy of the OKSM cassette (named the Collagen-OKSM repro- grammable mouse strain) developed by Dr. Konrad Hochedlinger, ${ }^{51}$ both strains which contain a single copy of the reprogramming gene cassette in the same Collal locus, indicated that the Collagen-OKSM reprogrammable strain had an increased mortality due to high tumor incidents. ${ }^{52}$ In the B6/129 ${ }^{\mathrm{OKSM}}$ strain, we did not observe similar abnormalities reported in the Collagen-OKSM reprogrammable mouse strain; eight incidents per 551 live births were confirmed in the B6/129 ${ }^{\text {OKSM }}$ strain within a 4-month period of observation. The B6/129 ${ }^{\text {OKSM }}$ strain was developed from three independent iPSC lines reprogrammed from fibroblast-like cells as shown in Figure 1A and used a STEM-CCA lentiviral vector to introduce an OKSM cassette, integration of which does not occur at specific genomic loci. ${ }^{53,54}$ After over 10 generations of crossbreeding, we selected the strain that carried a single copy of the OKSM cassette and induced high iPSC formation from peripheral blood cells. We have confirmed that there were at least four independent integration sites in those iPSC lines used for chimeric mouse generation by PCR-based vector integration site analysis, ${ }^{36}$ and that one of those sites located in chromosome six was maintained in the B6/129 ${ }^{\text {OKSM }}$ strain. Importantly, the high level of iPSC formation from peripheral blood cells was inherited even after backcrossing to B6 strain for over 10 generations 
A

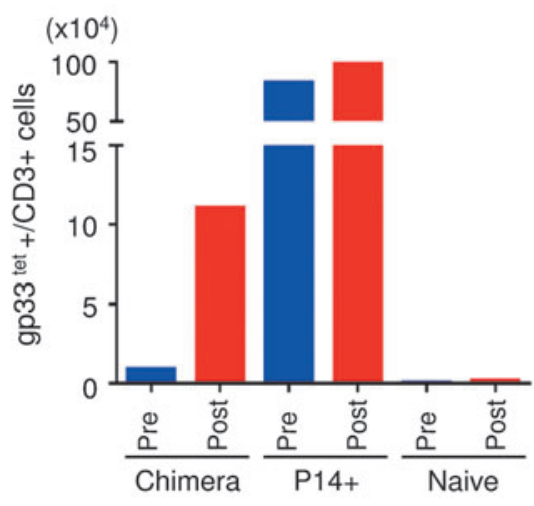

B

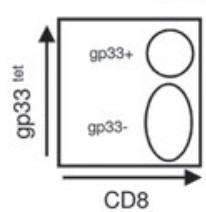

Unstimulated
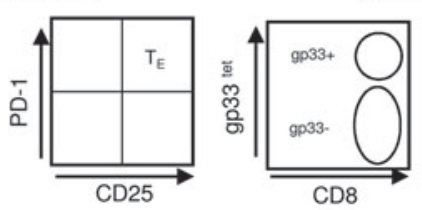

Stimulated

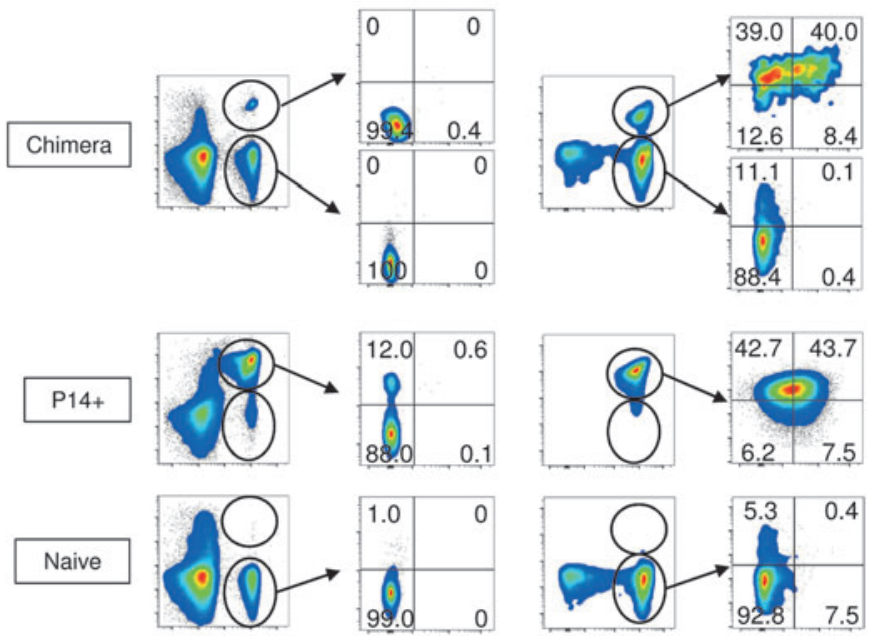

FIG. 6. Antigen-specific activation of redifferentiated T cells from iPSCs originated from exhausted LCMV-specific T cells in vitro. Peripheral blood cells obtained from the chimeric mouse shown in Figure 5 (Chimera) were pulsed with $1 \mu \mathrm{g} /$ $\mathrm{ml}$ of LCMV-derived gp33-41 peptide (KAVYNFATM) for $2 \mathrm{~h}$ in the presence of anti-mouse CD28 antibody (1 $\mu \mathrm{g} / \mathrm{ml})$. Cells were then cultured for 3 days in the presence of $5 \mathrm{ng} / \mathrm{ml}$ of IL-7 and IL-15. (A) LCMV gp33-specific CD8 T cells were analyzed by flow cytometry following staining with mouse CD3 and CD8 antibodies together with LCMV-specific gp33 tetramer (gp33 ${ }^{\text {tet }}$ ). Total cell numbers of LCMV gp33-specific CD8 T cells in $10^{6}$ CD3 ${ }^{+}$cells were determined pre- or postgp33 peptide pulsing using FlowJo software. (B) Cell surface phenotypes of LCMV gp33-positive or -negative CD8 T cells were analyzed for CD25 and PD-1 expression pre- or post-gp33 peptide pulsing. Naive B6/129 OKSM (Naive) and P14+ B6/ $129^{\mathrm{OKSM}}(\mathrm{P} 14+)$ were used as negative and positive controls for LCMV gp33 peptide-dependent T cell activation, respectively. Numbers in PD-1/CD25 panels indicate the percentage of the parent gate.

(data not shown), suggesting that the integration site of the OKSM cassette is more important for efficient iPSC formation from blood lineage cells than the genetic background of the mouse strain. A detailed analysis of the relationship between reprogramming efficiency and the vector integration site is currently ongoing.

An adoptive transfer of functionally restored antigenspecific CD8 T cells to naive mice (i.e., cellular vaccine) or pre-infected mice (i.e., adoptive cell therapy) may be more practically relevant for clinical application. Such an attempt at adoptive transfer was unsuccessful due to insufficient LCMV-specific CD8 T cell development with our strategy using chimeric mouse generation (Fig. 5). We have no clear answer for this low donor chimerism observed with iPSCs generated from exhausted LCMV-specific CD8 T cells. As an alternative approach, we are currently attempting to differentiate those iPSCs into $\mathrm{T}$ cells in vitro using an OP9 coculture system. ${ }^{55,56}$

The ultimate goal is to extend our studies into the clinical setting by reprogramming exhausted $\mathrm{T}$ cells specific to HIV proteins isolated from chronically HIV-infected patients. However, three technical advancements are needed for this research agenda: (1) reprogramming of exhausted antigenspecific $\mathrm{T}$ cells into iPSCs with exogenous reprogramming factors/conditions, (2) redifferentiate established iPSC lines into functional T cells in vitro, and (3) pre-expand those T cells to obtain a sufficient number of cells. All these technological advancements would make our concept a practical approach.

\section{Authors' Contributions}

M.K. designed the research, performed the experiments, analyzed data, and wrote the article. J.C., P.Y.K., E.K., Y.N., Y.L., J.W., H.J.E., M.Q., and G.E.R. performed the experiments. D.G.B. and I.S.Y.C interpreted data.

\section{Acknowledgments}

This work was supported by the California HIV/AIDS Research Grants Program (ID13-LA-563 to M.K.), UCLA AIDS Institute Mentorship Grant for Transitional Investigators (M.K.), NIH grant AI110200 (M.K.), NIH grant AI085043 (D.G.B), BSCRC Innovation Award (I.S.Y.C.), RS1-CIRM 00172-1 (I.S.Y.C), and Bill \& Melinda Gates Foundation (I.S.Y.C). Cell sorting was performed in the CFAR Flow Cytometry Core Facility supported by NIH grants P30 CA016042 and 5P30 AI028697.

Tetramers specific to LCMV gp33-41 and LCMV gp276286 were generated at the NIH Tetramer Facility.

\section{Author Disclosure Statement}

All authors declare no competing financial interests. 


\section{References}

1. Wherry E, Ha S, Kaech S, et al.: Molecular signature of CD8+ $\mathrm{T}$ cell exhaustion during chronic viral infection. Immunity 2007;27:670-684.

2. Wherry EJ, Kurachi M: Molecular and cellular insights into T cell exhaustion. Nat Rev Immunol 2015;15:486-499.

3. Moskophidis D, Lechner F, Pircher H, Zinkernagel RM: Virus persistence in acutely infected immunocompetent mice by exhaustion of antiviral cytotoxic effector $\mathrm{T}$ cells. Nature 1993;362:758-761.

4. Gallimore A, Glithero A, Godkin A, et al.: Induction and exhaustion of lymphocytic choriomeningitis virus-specific cytotoxic $\mathrm{T}$ lymphocytes visualized using soluble tetrameric major histocompatibility complex class I-peptide complexes. J Exp Med 1998;187:1383-1393.

5. Zajac AJ, Blattman JN, Murali-Krishna K, et al.: Viral immune evasion due to persistence of activated $\mathrm{T}$ cells without effector function. J Exp Med 1998;188:2205-2213.

6. Day CL, Kaufmann DE, Kiepiela P, et al.: PD-1 expression on HIV-specific T cells is associated with T-cell exhaustion and disease progression. Nature 2006;443:350-354.

7. Dyavar Shetty R, Velu V, Titanji K, et al.: PD-1 blockade during chronic SIV infection reduces hyperimmune activation and microbial translocation in rhesus macaques. $J$ Clin Invest 2012;122:1712-1716.

8. Petrovas C, Price DA, Mattapallil J, et al.: SIV-specific CD8+ T cells express high levels of PD1 and cytokines but have impaired proliferative capacity in acute and chronic SIVmac251 infection. Blood 2007;110:928-936.

9. Yamamoto T, Price DA, Casazza JP, et al.: Surface expression patterns of negative regulatory molecules identify determinants of virus-specific CD8+ T-cell exhaustion in HIV infection. Blood 2011;117:4805-4815.

10. Gruener NH, Lechner F, Jung MC, et al:: Sustained dysfunction of antiviral CD8+ T lymphocytes after infection with hepatitis C virus. J Virol 2001;75:5550-5558.

11. Radziewicz H, Ibegbu CC, Fernandez ML, et al.: Liverinfiltrating lymphocytes in chronic human hepatitis $\mathrm{C}$ virus infection display an exhausted phenotype with high levels of PD-1 and low levels of CD127 expression. J Virol 2007;81:2545-2553.

12. Reignat S, Webster GJ, Brown D, et al.: Escaping high viral load exhaustion: CD8 cells with altered tetramer binding in chronic hepatitis B virus infection. J Exp Med 2002;195:1089-1101.

13. Urbani S, Boni C, Missale G, et al.: Virus-specific CD8+ lymphocytes share the same effector-memory phenotype but exhibit functional differences in acute hepatitis B and C. J Virol 2002;76:12423-12434.

14. Wherry EJ: T cell exhaustion. Nat Immunol 2011;12:492499.

15. Jin HT, Jeong YH, Park HJ, Ha SJ: Mechanism of T cell exhaustion in a chronic environment. BMB Rep 2011;44: 217-231.

16. Yi JS, Cox MA, Zajac AJ: T-cell exhaustion: Characteristics, causes and conversion. Immunology 2010;129:474-481.

17. Barber DL, Wherry EJ, Masopust $\mathrm{D}$, et al.: Restoring function in exhausted CD8 $\mathrm{T}$ cells during chronic viral infection. Nature 2006;439:682-687.

18. Palmer BE, Neff CP, Lecureux J, et al:: In vivo blockade of the PD-1 receptor suppresses HIV-1 viral loads and improves CD4+ T cell levels in humanized mice. J Immunol 2013;190:211-219.
19. Finnefrock AC, Tang A, Li F, et al.: PD-1 blockade in rhesus macaques: Impact on chronic infection and prophylactic vaccination. J Immunol 2009;182:980-987.

20. Velu V, Titanji K, Zhu B, et al.: Enhancing SIV-specific immunity in vivo by PD-1 blockade. Nature 2009;458:206210.

21. Haymaker C, Wu R, Bernatchez C, Radvanyi L: PD-1 and BTLA and CD8(+) T-cell "exhaustion" in cancer: "Exercising" an alternative viewpoint. Oncoimmunology 2012;1:735-738.

22. Utzschneider DT, Legat A, Fuertes Marraco SA, et al.: T cells maintain an exhausted phenotype after antigen withdrawal and population reexpansion. Nat Immunol 2013;14: 603-610.

23. Garidou L, Heydari S, Truong P, Brooks DG, McGavern DB: Therapeutic memory $T$ cells require costimulation for effective clearance of a persistent viral infection. J Virol 2009;83:8905-8915.

24. Lau GK, Suri D, Liang R, et al:: Resolution of chronic hepatitis $\mathrm{B}$ and anti-HBs seroconversion in humans by adoptive transfer of immunity to hepatitis B core antigen. Gastroenterology 2002;122:614-624.

25. Walter EA, Greenberg PD, Gilbert MJ, et al.: Reconstitution of cellular immunity against cytomegalovirus in recipients of allogeneic bone marrow by transfer of T-cell clones from the donor. N Engl J Med 1995;333:1038-1044.

26. Papp B, Plath K: Epigenetics of reprogramming to induced pluripotency. Cell 2013;152:1324-1343.

27. Doering TA, Crawford A, Angelosanto JM, Paley MA, Ziegler CG, Wherry EJ: Network analysis reveals centrally connected genes and pathways involved in CD8+ T cell exhaustion versus memory. Immunity 2012;37:1130-1144.

28. Hoffman R, Jamieson B, Bosch R, et al.: Baseline immune phenotypes and $\mathrm{CD} 4+\mathrm{T}$ lymphocyte responses to antiretroviral therapy in younger versus older HIV-infected individuals. J Clin Immunol 2011;31:873-881.

29. Nishimura $\mathrm{T}$, Kaneko S, Kawana-Tachikawa A, et al.: Generation of rejuvenated antigen-specific $\mathrm{T}$ cells by reprogramming to pluripotency and redifferentiation. Cell Stem Cell 2013;12:114-126.

30. Brooks DG, McGavern DB, Oldstone MB: Reprogramming of antiviral $\mathrm{T}$ cells prevents inactivation and restores $\mathrm{T}$ cell activity during persistent viral infection. J Clin Invest 2006;116:1675-1685.

31. Urbani $\mathrm{S}$, Amadei $\mathrm{B}$, Tola $\mathrm{D}$, et al.: PD-1 expression in acute hepatitis $\mathrm{C}$ virus (HCV) infection is associated with HCV-specific CD8 exhaustion. J Virol 2006;80:1139811403.

32. Wilson EB, Brooks DG: Translating insights from persistent LCMV infection into anti-HIV immunity. Immunol Res 2010;48:3-13.

33. Jackson M, Taylor AH, Jones EA, Forrester LM: The culture of mouse embryonic stem cells and formation of embryoid bodies. Methods Mol Biol 2010;633:1-18.

34. Carey BW, Markoulaki S, Beard C, Hanna J, Jaenisch R: Single-gene transgenic mouse strains for reprogramming adult somatic cells. Nat Methods 2010;7:56-59.

35. Sommer CA, Stadtfeld M, Murphy GJ, Hochedlinger K, Kotton DN, Mostoslavsky G: Induced pluripotent stem cell generation using a single lentiviral stem cell cassette. Stem Cells 2009;27:543-549.

36. Kim S, Kim N, Presson AP, et al.: High-throughput, sensitive quantification of repopulating hematopoietic stem cell clones. J Virol 2010;84:11771-11780. 
37. Smelt SC, Borrow $\mathrm{P}$, Kunz $\mathrm{S}$, et al.: Differences in affinity of binding of lymphocytic choriomeningitis virus strains to the cellular receptor alpha-dystroglycan correlate with viral tropism and disease kinetics. J Virol 2001;75:448-457.

38. Takahashi K, Yamanaka S: Induction of pluripotent stem cells from mouse embryonic and adult fibroblast cultures by defined factors. Cell 2006;126:663-676.

39. Buganim Y, Faddah DA, Jaenisch R: Mechanisms and models of somatic cell reprogramming. Nat Rev Genet 2013;14:427-439.

40. Hochedlinger K, Jaenisch R: Induced pluripotency and epigenetic reprogramming. Cold Spring Harb Perspect Biol 2015;7: pii: a019448.

41. Tanabe K, Takahashi K, Yamanaka S: Induction of pluripotency by defined factors. Proc Jpn Acad Ser B Phys Biol Sci 2014;90:83-96.

42. Mall M, Wernig M: The novel tool of cell reprogramming for applications in molecular medicine. J Mol Med (Berl) 2017;95:695-703.

43. Takahashi K, Yamanaka S: A decade of transcription factor-mediated reprogramming to pluripotency. Nat Rev Mol Cell Biol 2016;17:183-193.

44. Loh YH, Hartung O, Li H, et al.: Reprogramming of T cells from human peripheral blood. Cell Stem Cell 2010;7:15-19.

45. Eminli S, Foudi A, Stadtfeld M, et al.: Differentiation stage determines potential of hematopoietic cells for reprogramming into induced pluripotent stem cells. Nat Genet 2009;41:968-976.

46. Wernig M, Lengner CJ, Hanna J, et al.: A drug-inducible transgenic system for direct reprogramming of multiple somatic cell types. Nat Biotechnol 2008;26:916-924.

47. Wakeland E, Morel L, Achey K, Yui M, Longmate J: Speed congenics: a classic technique in the fast lane (relatively speaking). Immunol Today 1997;18:472-477.

48. Ahmed R, Salmi A, Butler LD, Chiller JM, Oldstone MB: Selection of genetic variants of lymphocytic choriomeningitis virus in spleens of persistently infected mice. Role in suppression of cytotoxic $\mathrm{T}$ lymphocyte response and viral persistence. J Exp Med 1984;160:521-540.
49. An D, Donahue R, Kamata M, et al:: Stable reduction of CCR5 by RNAi through hematopoietic stem cell transplant in non-human primates. Proc Natl Acad Sci U S A 2007; 104:13110-13115.

50. Brandle D, Brduscha-Riem K, Hayday AC, Owen MJ, Hengartner $\mathrm{H}$, Pircher $\mathrm{H}$ : T cell development and repertoire of mice expressing a single $\mathrm{T}$ cell receptor alpha chain. Eur J Immunol 1995;25:2650-2655.

51. Stadtfeld M, Maherali N, Borkent M, Hochedlinger K: A reprogrammable mouse strain from gene-targeted embryonic stem cells. Nat Methods 2010;7:53-55.

52. Carey BW, Markoulaki S, Hanna JH, et al.: Reprogramming factor stoichiometry influences the epigenetic state and biological properties of induced pluripotent stem cells. Cell Stem Cell 2011;9:588-598.

53. Kim S, Kim N, Presson AP, et al.: Dynamics of HSPC repopulation in nonhuman primates revealed by a decadelong clonal-tracking study. Cell Stem Cell 2014;14:473485.

54. Ciuffi A, Mitchell RS, Hoffmann C, et al.: Integration site selection by HIV-based vectors in dividing and growtharrested IMR-90 lung fibroblasts. Mol Ther 2006;13:366373.

55. Lei F, Haque R, Xiong X, Song J: Directed differentiation of induced pluripotent stem cells towards $\mathrm{T}$ lymphocytes. J Vis Exp 2012;63:e3986.

56. Wada H, Kojo S, Kusama C, et al.: Successful differentiation to $\mathrm{T}$ cells, but unsuccessful B-cell generation, from B-cell-derived induced pluripotent stem cells. Int Immunol 2011;23:65-74.

Address correspondence to:

Masakazu Kamata

Division of Hematology and Oncology David Geffen School of Medicine at UCLA 615 Charles East Young Drive South, BSRB 157(12A) Los Angeles, CA 90095

E-mail: masa3k@ucla.edu 